\title{
Tecnologia de duplo haploide na determinação da herança da resistência à podridão de colmo (Fusarium verticilioides) em linhagens de milho
}

\author{
Luciano Rodrigo Rosa ${ }^{1,2}$; Marcus Reis Sena ${ }^{3}$; Humberto Franco Shiomi ${ }^{4}$
}

\begin{abstract}
${ }^{1}$ Luciano Rodrigo Rosa - Mestrando em agronomia - Universidade Federal do Mato Grosso - UFMT, campus Sinop. ${ }^{2}$ Parte de dissertação de mestrado. ${ }^{3}$ Marcus Reis Sena - Melhorista da empresa Dow Agrosciences Sementes Biotecnologia Brasil LTDA. Sorriso - MT. ${ }^{4}$ Humberto Franco Shiomi - Professor Adjunto nas áreas de Microbiologia e Nematologia Agrícola, nos cursos de graduação em Agronomia, Engenharia Agrícola e Ambiental e Zootecnia e em Nematologia e Doenças das Grandes Culturas, no curso de Pós-Graduação em Agronomia (Mestrado) - Área de Concentração - Fitotecnia, da Universidade Federal do Mato Grosso - UFMT, campus Sinop.
\end{abstract}

Autor para correspondência: Luciano Rodrigo Rosa (lrrosa@dow.com)

Data de chegada: 21/05/2015. Aceito para publicação em: 29/07/2015.

$10.1590 / 0100-5405 / 2096$

\section{RESUMO}

Rosa, L.R.; Sena, M.R.; Shiomi, H.F. Tecnologia de duplo haploide na determinação da herança da resistência à podridão de colmo (Fusarium verticilioides) em linhagens de milho. Summa Phytopathologica, v.42, n.1, p.59-66, 2016.

Foram utilizadas no trabalho quatro populações sintetizadas pelo cruzamento de duas linhagens homozigotas contrastantes quanto a resistência a F.verticilioides. Para a obtenção das linhagens haploides destas populações as mesmas foram cruzadas com indutor de haploidia, os haploides foram então duplicados e autofecundados, sendo as sementes colhidas fonte de origem das linhagens usadas no trabalho. Aos 70 dias após a semeadura as linhagens foram inoculadas com suspensão de esporos do patógeno F.verticilioides em concentração de $210^{6}$ esporos por $\mathrm{mL}$ e com 70 dias após a inoculação as espigas foram colhidas e pesadas e os colmos foram coletados, pesados e medidos em comprimento e diâmetro e seccionados longitudinalmente para avaliações dos sintomas, onde também foram medidos os comprimentos das lesões. Foram estimadas às variâncias fenotípica, ambiental, genotípica total e entre e dentro famílias, além da herdabilidade e da variância aditiva e de dominância. A variância devido a efeitos genéticos dominantes foram de maior magnitude, sendo que a herdabilidade no sentido restrito foi de 0,28 . A distribuição de frequência observada podem indicar efeitos epistáticos envolvidos no controle genético da resistência a F.verticilioides. Os maiores ganhos esperados com a seleção foram alcançados com o emprego de seleção entre família e seleção massal.

Palavras-chave: Safrinha, Herdabilidade, Zea mays L

\section{ABSTRACT}

Rosa, L.R.; Sena, M.R.; Shiomi, H.F. Double haploid technology to determine the inheritance of resistance to stalk rot (Fusarium verticilioides) in corn inbred lines. Summa Phytopathologica, v.42, n.1, p.59-66, 2016.

Were used in the study four populations synthesized by crossing two contrasting inbred lines as resistance to F.verticilioides. To obtain haploid inbred lines of these populations were crossed with haploid inducer, the haploid lines were then duplicated and selfed, and the seeds harvested were the of origin of the inbred lines used in the study. Seventy days after sowing the inbred lines were inoculated with a suspension of spores of the pathogen in F.verticilioides concentration of 2106 spores and 70 days after inoculation the ears were harvested and weighed and stalks were collected, weighed and measured in length and diameter and longitudinally sectioned for evaluation of symptoms, which were also the lengths of the lesions measured. They were estimated to phenotypic, environmental variances, full genotypic and between and within families, as well as heritability and additive variance and dominance. The variance due to dominant genetic effects was greatest magnitude, and the heritability in the narrow sense was 0.28 . The observed frequency distribution may indicate epistatic effects involved in the genetic control of resistance to F.verticilioides. The biggest gains expected with the selection were achieved with the use of selection among families and mass selection.

Keywords: Off season, Inheritability, Zea mays $L$.

Para a obtenção do milho híbrido, existem três etapas sendo a primeira delas a obtenção das linhagens endogâmicas, depois o teste de capacidade de combinação para identificar as melhores combinações, e por fim a produção e comercialização das cultivares híbridas. Dentre estas etapas, a obtenção de linhagens é a mais demorada e de custo elevado. Isto porque, para atingir a homozigose, são necessárias de seis a oito gerações de endogamia (13).

No Brasil, a safrinha de milho vem ganhando espaço ano após ano. Nos últimos anos houve um crescimento na área plantada em $49,3 \%$, sendo responsável atualmente, por $58 \%$ dos grãos de milho produzidos. (4)

Este sistema de cultivo se consolidou no estado de Mato Grosso, onde a cultura é plantada após a colheita da soja de verão. Na última safra ocupou $37,4 \%$ (4) da área semeada com soja, tornando o estado o maior produtor de milho safrinha do país.

Para redução dos custos de produção, os agricultores se aproveitam do clima seco de final do ciclo, para que os grãos atinjam umidade ideal de armazenamento. Para isso as plantas permanecem por prolongados períodos expostas por mais tempo à ação de fungos causadores de podridões de colmo. As podridões de colmo na cultura do milho são 
as maiores responsáveis pela redução de produtividade, afetando o rendimento potencial e a qualidade dos grãos e dificultando a colheita. (11).

Após o enchimento dos grãos, as perdas se devem ao tombamento das plantas, que difículta a realização da colheita mecânica, causando prejuízos pelo apodrecimento das espigas em contato com o solo ou elevando os custos de produção em casos de necessidade de catação manual das espigas. (6).

Para se ter sucesso neste sistema de produção, híbridos comerciais devem possuir tolerância ás doenças de colmo, principalmente às podridões causadas por F.verticilioides, visto que as condições de campo são favoráveis ao desenvolvimento deste patógeno.

A podridão por $F$. verticilioides ocorre em tecidos senescentes, pois estes apresentam baixos teores de carboidratos e substâncias fungistáticas (8). Esta condição ocorre no final de ciclo ou quando as plantas sofrem estresse. Normalmente, os sintomas aparecem após a polinização, aumentando a severidade próxima à maturação (9). Os tecidos dos nós e entrenós tornam-se avermelhados, progredindo da base para o ápice (15). Com o avanço da doença, ocorre o fendilhamento dos tecidos, os quais adquirem semelhança à consistência de isopor. $\mathrm{O}$ enfraquecimento do colmo causa a quebra prematura das plantas (9). As condições ambientais que favorecem o desenvolvimento do fungo são temperaturas em torno de $30^{\circ} \mathrm{C}$ e altitudes abaixo de $700 \mathrm{~m}(8$, 15) condições estas que predominam em grande parte da área plantada com a cultura do milho no estado de Mato Grosso.

No processo de desenvolvimento de híbridos comerciais de milho a obtenção de linhagens endogâmicas é a etapa mais demorada e que apresenta maiores custos devido à necessidade de grande mão de obra para realização do processo de autofecundação (13). São necessários sete ciclos sucessivos de autofecundação e cruzamentos de progênies com testadores para identificar linhagens com potencial produtivo elevado.

Dentro dos programas de melhoramento das empresas de sementes de milho, uma ferramenta que tem se destacado nos últimos anos é a tecnologia de duplo-haploide. Essa tecnologia vem sendo amplamente utilizada para a geração de grande quantidade de linhagens endogâmicas em um período mais curto de tempo quando comparado ao método convencional. Esta tecnologia tem potencializado os programas de melhoramento pois permite uma drástica redução de mão de obra, ganho de tempo e possibilidade de se avaliar um maior número de individuos devido à maior rapidez em que os híbridos podem ser gerados.

A determinação da herança à podridão de colmo causada por F.verticilioides seria uma forma de aumentar a eficiência da metodologia, tornando a ferramenta mais eficiente e assim contribuindo para o controle desta doença importante no sistema de produção de milho.

O presente trabalho teve por objetivo determinar a herança da podridão de colmo causada por F.verticilioides em linhagens de milho obtidas através da tecnologia duplo haploide.

\section{MATERIAL E MÉTODOS}

O experimento foi conduzido no município de Sorriso-MT no ano de 2014, na estação de pesquisa da empresa de sementes Dow AgroSciences. O plantio foi realizado no mês de fevereiro, período que corresponde ao plantio da segunda safra no estado. A estação de pesquisa situa-se a $12^{\circ} 32^{\prime} 43^{\prime}$ 'S de latitude, $55^{\circ} 42^{\prime} 41^{\prime}$ 'W de longitude e $350 \mathrm{~m}$ de altitude.

O delineamento experimental empregado foi o de blocos casualizados com três repetições. As parcelas experimentais foram constituídas por linhas de $1,2 \mathrm{~m}$ de comprimento, espaçadas a 0,50 $\mathrm{m}$ com estande médio de cinco plantas por linha, correspondendo a densidade de plantas de $83.300 \mathrm{ha}^{-1}$. O plantio foi realizado com semeadoras manuais colocando-se uma semente por cova. A adubação de semeadura foi de $36 \mathrm{~kg} \cdot \mathrm{ha}^{-1}$ de $\mathrm{N}, 72 \mathrm{~kg} \cdot$ ha ${ }^{-1}$ de $\mathrm{P}_{2} \mathrm{O}_{5}$ e $72,0 \mathrm{~kg} \cdot \mathrm{ha}^{-1}$ de $\mathrm{K}_{2} \mathrm{O}$. A adubação de cobertura foi efetuada com 90 $\mathrm{kg} \cdot \mathrm{ha}^{-1} \mathrm{de} \mathrm{N}$, divididos em duas aplicações aos 15 e 25 dias de plantio respectivamente.

O tratamento das sementes foi realizado com o inseticida Imidacloprido + Tiodicarbe $\left(0,3 \mathrm{~L}\right.$. ha $\left.{ }^{-1}\right)$ e também o fungicida Fludioxonil + Mefenoxam (0,3 L. ha $\left.{ }^{-1}\right)$ Para o controle de pragas, três aplicações de inseticidas foram necessárias, sendo a primeira entre os estádios V6 e V7, com o inseticida Espinosade (0,1L ha $\left.{ }^{-1}\right)$. A segunda aplicação foi efetuada no estádio V12, de pré-pendoamento com o inseticida Clorpirifos (60 $\left.\mathrm{mL} \mathrm{ha}^{-1}\right)$ e a terceira aplicação, no início do florescimento, R1, com os inseticida Lambda-Cialotrina $(0,1$ $\mathrm{L} \mathrm{ha}^{-1}$ ) Para o controle de plantas daninhas foi realizada a aplicação dos herbicidas Tembotriona $\left(240 \mathrm{~mL} \mathrm{ha}^{-1}\right)$ e Atrazina $\left(2 \mathrm{~L} \mathrm{ha}^{-1}\right)$ e o adjuvante Aureo $\left(600 \mathrm{~mL} \mathrm{ha}^{-1}\right)$, entre os estádios V6 e V7.

Para evitar influência no desenvolvimento do patógeno não foi aplicado fungicida no experimento.

Para obtenção das linhagens utilizadas no trabalho foram sintetizadas quatro populações cada qual oriunda do cruzamento de duas linhagens homozigotas contrastantes quanto a tolerância ao patógeno F.verticilioides. Foram cruzadas 20 plantas de cada um dos parentais e estas populações foram denominadas de J24/T61, J14/J77, G23/ M20 e J67/T66 ( Tabela 1) sendo o número de tratamentos avaliados em cada uma delas, incluindo-se os parentais e o F1 de 49, 80, 58 e 21 respectivamente.

As populações F1 foram induzidas à haploidia, sendo cruzadas com o indutor. Posteriormente as sementes putativas haploides de cada uma das populações foram selecionadas, observando-se a marcação nos grãos, onde aqueles com endosperma roxo e embrião branco foram selecionados como putativos haploide. Os putativos foram levados ao laboratório seguindo o protocolo proposto por Deimling et al; (7) onde após pré-germinação as plântulas foram tratadas com solução de colchicina a $0,06 \%+0,5 \%$ de dimetil sulfóxido, por 12 horas no escuro e mantidas em temperatura ambiente. Após a duplicação, as plântulas foram lavadas por 20 minutos em água corrente e então, transplantadas em bandejas plásticas com substrato vegetal e levadas para casa de vegetação. Após 10 dias as plantas foram levadas a campo para o desenvolvimento. Quando as plantas floresceram, foi realizada a autofecundação e as sementes colhidas deram origem às linhagens endogâmicas utilizadas no trabalho.

\section{Teste de patogenicidade}

Foi realizado um teste prévio para checar o nível de patogenicidade do isolado que poderia ser utilizado na inoculação do experimento. Este isolado foi obtido de plantas coletadas em lavouras de milho no município de Sorriso - MT e o desenvolvimento em placa de petri com meio de cultura BDA. O inóculo foi preparado e a inoculação em uma linhagem sucestível foi realizada aos 70 dias de plantio, utilizando-se de três tratamentos, sendo o primeiro a injeção no centro do segundo internódio $1 \mathrm{~mL}$ de suspensão de esporos de F.verticilioides na concentração de $210^{6}$ esporos por $\mathrm{mL}$. O segundo tratamento também foi a injeção no segundo internódio de água destilada esterilizada e o terceiro tratamento a testemunha sem inoculação. Após 70 dias da inoculação foi realizada a avaliação, onde os colmos foram coletados e seccionados longitudinalmente para a avaliação dos sintomas, onde se 
Tabela 1. Nível de resistência dos parentais e Grupos Heteróticos de populações sintetizadas.

\begin{tabular}{|c|c|c|c|c|}
\hline $\begin{array}{c}\text { Nome das } \\
\text { Linhas Parentais }\end{array}$ & $\begin{array}{l}\text { Nível de Resistência a } \\
\text { Fusarium verticilioides* }\end{array}$ & $\begin{array}{c}\text { Grupo } \\
\text { heterótico }\end{array}$ & $\begin{array}{l}\text { Nome das } \\
\text { Populações }\end{array}$ & $\begin{array}{c}\mathbf{N}^{0} \text { de linhas } \\
\text { Geradas }\end{array}$ \\
\hline $\mathrm{J} 24$ & $\mathrm{R}$ & Tuxpeño & & \\
\hline $\mathrm{J} 14$ & $\mathrm{R}$ & Suwan & & \\
\hline $\mathrm{J} 77$ & MS & Suwan & $\mathrm{J} 14 / \mathrm{J} 77$ & 77 \\
\hline M20 & MS & Tuxpeño & G23/M20 & 55 \\
\hline J67 & $\mathrm{R}$ & Tuxpeño & & \\
\hline T66 & $\mathrm{S}$ & Cateto & J67/T66 & 18 \\
\hline
\end{tabular}

* Nível de tolerância a Fusarium verticilioides onde $\mathrm{R}=$ Resistente, $\mathrm{S}=$ Suscetível, MR= Médio Resistente, MS = Médio Suscetível.

pode observar que o tratamento onde foi inoculado as áreas lesionadas de tamanho satisfatório, mostrando a capacidade do patógeno em causar a doença com severidade suficiente para uma avaliação consistente e confiável.

Produção e preparo do inoculo.

O patógeno foi multiplicado em meio de cultura de grãos de sorgo com objetivo de obtenção do volume necessário para realizar a inoculação do experimento. Os grãos utilizados como meio de cultura foram colocados em volume de $250 \mathrm{~mL}$ em Erlenmeyers de capacidade de $500 \mathrm{~mL}$. A estes foi adicionado $100 \mathrm{~mL}$ de água destilada e então foram levados à esterilização em autoclave por meia hora a $121^{\circ} \mathrm{C}$. Após resfriamento o patógeno, previamente cultivado em placas de Petri em meio de cultura BDA, foi transferido para os Erlenmeyers em câmara de fluxo laminar e levados para câmara de crescimento B.O.D para incubação onde permaneceram em regime alternado de luz de 12 horas por 15 dias à temperatura de $25^{\circ} \mathrm{C}$.

O inóculo foi preparado para a inoculação utilizando-se água destilada com adição de Tween 80 na concentração de $1 \mathrm{~mL}$ por litro. Duzentos e cinquenta mililitros de água esterilizada foram então adicionados aos Erlenmeyers onde o patógêno foi incubado, sendo agitados manualmente para a liberação dos esporos em suspensão. A suspensão foi então filtrada em peneira de malha de $2 \mathrm{~mm}$ por várias vezes para facilitação de observação ao microscópio. Procedeu-se com o auxílio de câmara de Neubauer a estimativa do número médio de conídios para posterior calibração da suspensão de esporos ajustando a concentração utilizada para a inoculação com $210^{6}$ esporos por $\mathrm{mL}$.

\section{Inoculação}

Aos 70 dias pós-plantio, período correspondente ao término do florecimento das plantas, foi realizada a inoculação injetando-se $1 \mathrm{~mL}$ da suspensão de esporos, no centro do segundo internódio, utilizando inoculador apropriado à penetração no colmo das plantas.

\section{Avaliação}

A avaliação foi realizada 70 dias após a inoculação, onde as espigas foram colhidas e levadas ao secador de sementes para posterior debulha e pesagem dos grãos. Foram retiradas as folhas já secas e os colmos foram cortados na parte superior no ponto de inserção da espiga e na parte inferior na base do solo. Os colmos devidamente identificados pelo número de parcela foram recolhidos do campo para posterior avaliação. Os colmos foram seccionados no sentido longitudinal para exposição dos sintomas e assim foram realizadas as medições, para determinação do comprimento e tamanho de lesão, utilizando-se trena, para medir o diâmetro foi utilizado um paquímetro, o peso dos colmo e dos grãos foi avaliado com uma balança digital. Os dados foram utilizados para determinação da densidade, cálculo da porcentagem de área lesionada e produção de grãos.

Os colmos, após as medições, foram colocados em secador de sementes para ventilação até peso constante. O peso final foi utilizado para cálculo da densidade. Por fim, foram coletadas 40 amostras de colmo de forma aleatória para realizar o reisolamento do patógeno e levado ao laboratório, após reisolamento, vindo a confirmar como agente causal das lesões F.verticilioides.

Análises de características agronômicas e estimativa de componentes de variância.

Foram avaliadas as quatro populações, incluindo os genitores e as linhagens sintetizadas através de duplo-haploidia para as características: peso de espigas, porcentagem de lesão e densidade de colmo.

Os dados originais destas características não apresentaram distribuição normal. Assim foram necessárias as suas transformações usando-se logaritmo para peso de espigas e raiz quadrada para a porcentagem de lesão e densidade de colmo.

Para a estimativa dos componentes de variância entre os cruzamentos foi utilizada a rotina de Indivíduos $\mathrm{Ft}$ e linhas $\mathrm{Ft}+1$ Derivadas dentro de Gerações Segregantes e Não Segregantes do software Genes, descrita por Cruz (5). Com esta rotina foi possível a estimativa da variância fenotípica, ambiental, genotípica total e entre e dentro famílias, além da herdabilidade e da variância aditiva e de dominância.

\section{RESULTADOS E DISCUSSÃO}

\section{Análise de características agronômicas.}

Observou-se, para a variável peso de espiga, (Tabela 2) que todos os tratamentos de todos os cruzamentos apresentaram diferença significativa ao nível de $1 \%$ de probabilidade. As populações J14/J77 e G23/M20 apresentaram as maiores médias com pesos de 174,53 g e 181,14 g respectivamente. A população J67/T66 apresentou a maior amplitude entre os dados.

Com relação á porcentagem de área lesionada, houve diferença significativa entre as linhagens de todas as populações (Tabela 3 ) Os dados variaram de $20 \%$ na população G23/M20 a $99 \%$ na população J14/J77. A maior amplitude de variação foi na população J14/J77 indo de uma lesão de $28 \%$ a $99 \%$. A população G23/M20 foi a que 
Tabela 2. Resumo da análise de variância do peso de espigas das populações estudadas

\begin{tabular}{|c|c|c|c|c|c|c|c|c|}
\hline \multirow[b]{2}{*}{$\mathrm{FV}$} & \multicolumn{2}{|c|}{ J24/T61 } & \multicolumn{2}{|c|}{ J14/J77 } & \multicolumn{2}{|c|}{ G23/M20 } & \multicolumn{2}{|c|}{ J67/T66 } \\
\hline & GL & QM & GL & QM & GL & QM & GL & QM \\
\hline Bloco & 2 & 0,0136 & 2 & 0,0472 & 2 & 0,1126 & 2 & 0,0391 \\
\hline Resíduo & 96 & 0,0372 & 158 & 0,0221 & 116 & 0,0308 & 42 & 0,0275 \\
\hline Total & 146 & & 239 & & 176 & & 65 & \\
\hline CV (\%) & & 9,16 & & 6,77 & & 7,99 & & 8,35 \\
\hline Máx. & & 783,00 & & 395,00 & & 607,00 & & 476,00 \\
\hline Mín. & & 24,00 & & 32,00 & & 44,00 & & 38,00 \\
\hline
\end{tabular}

** Significativo a $1 \%$ de probabilidade pelo teste de $\mathrm{F}$.

apresentou a menor amplitude de variância indo de $20 \%$ a $53 \%$.

A população G23/M20 apresentou a menor média e variância de porcentagem de lesão mostrando que pode ser uma boa fonte de resistência à podridão de colmo causada por F.verticilioides.

Alguns genótipos apresentam características físicas no colmo, como a rigidez dos tecidos que contribuem para à resistência. Alguns trabalhos, como o de Borges et al.(2) mostram que o teor de lignina está diretamente correlacionado com a resistência ao patógeno.

Assim, a fim de se definir as características físicas dos colmos das populações avaliadas, calculou-se a densidade dos mesmos. Os dados de densidade evidenciaram que das quatro populações avaliadas, duas não apresentaram diferença significativa entre os tratamentos. (Tabela 4.) Apesar destas diferenças, as médias gerais ficaram bem próximas. Apesar da não significância, a população J24/T61 também foi a que apresentou a maior amplitude de variação.

Na Tabela 5, no teste de média da população J24/T61 pode-se observar a produtividade média de grãos, a densidade média de colmo e a porcentagem de comprimento de lesão dos parentais, F1 e linhas derivadas.

Para peso de espiga, observou-se segregação transgressiva significativa, já que algumas linhagens tiveram produção de espigas maiores que os parentais, (P1 e P2) sendo que 17 linhagens tiveram produtividade acima do melhor parental, no caso, J24.

No caso de seleção de novas linhagens mais produtivas e sadias, que é o objetivo do melhoramento, as linhagens 1 (JT11346), 11 (JT11355) e 35 (JT11384) apresentaram, em média, melhor produtividade per se e menores porcentagem de lesão se comparadas com seus parentais, assim, estas linhagens poderiam ser usadas para geração de populações com melhores produtividades de grãos e mais resistentes a podridão de colmo.

No caso das linhagens oriundas da população J14/J77, não se observou segregação transgressiva significativa para as três características estudadas. A linhagem que mais se destacou neste grupo foi o tratamento 2 (JJ11658) pois, apesar de não apresentar diferença significativa em relação ao melhor parental (J77) possui média superior, sendo assim, ela poderia ser usada como fonte de maior produtividade per se e maior resistência para geração de populações ou híbridos superiores.

Um outro grupo de linhagens é formado pelos tratamentos 14 (JJ11670), 39 (JJ11695) e 61 (JJ11717), que apresentaram desempenho bem interessante do ponto de vista do melhoramento, por terem sido ranqueadas em posições próximas ou até mesmo superiores ao melhor parental, sendo, também, possivelmente, fontes para geração de híbridos e novas populações superiores para as características avaliadas.

Tabela 3. Resumo da análise de variância das porcentagens de área lesionada causada por Fusarium verticilioides em colmos de milho das populações estudadas.

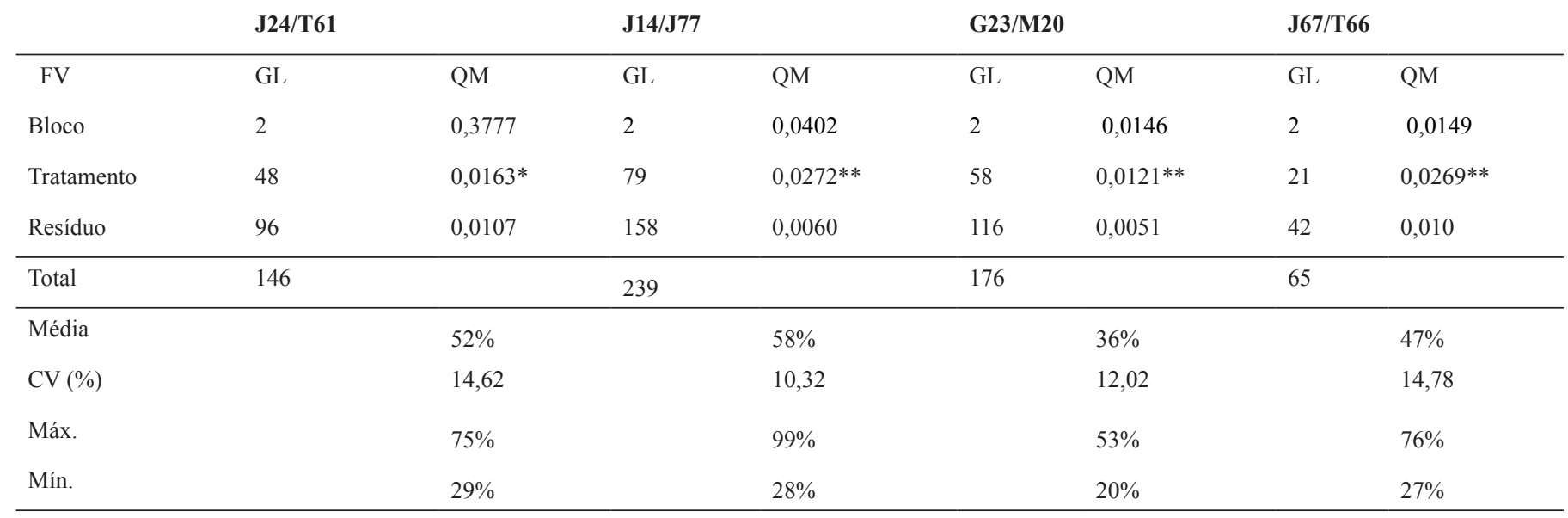

*** Significativo a $1 \%$ e a $5 \%$ de probabilidade pelo teste de $\mathrm{F}$, respectivamente. 
Tabela 4. Resumo da análise de variância da densidade de colmo das populações estudadas.

\begin{tabular}{|c|c|c|c|c|c|c|c|c|}
\hline \multirow[b]{2}{*}{$\mathrm{FV}$} & \multicolumn{2}{|l|}{ J24/T61 } & \multicolumn{2}{|c|}{ J14/J77 } & \multicolumn{2}{|c|}{ G23/M20 } & \multicolumn{2}{|c|}{ J67/T66 } \\
\hline & GL & $\mathrm{QM}$ & $\mathrm{GL}$ & $\mathrm{QM}$ & GL & QM & GL & QM \\
\hline Bloco & 2 & 0,0065 & 2 & 0,0031 & 2 & 0,0009 & 2 & 0,0025 \\
\hline Resíduo & 96 & 0,0079 & 158 & 0,0041 & 116 & 0,0039 & 42 & 0,0029 \\
\hline Total & 146 & & 239 & & 176 & & 65 & \\
\hline CV (\%) & & 15,01 & & 11,85 & & 11,83 & & 9,30 \\
\hline Máx. & & 0,820 & & 0,746 & & 0,467 & & 0,469 \\
\hline Mín. & & 0,235 & & 0,213 & & 0,206 & & 0,249 \\
\hline
\end{tabular}

** Significativo a $1 \%$ de probabilidade. * Significativo a $5 \%$ de probabilidade. Ns - Não significativo

Tabela 5. Teste de Média - População J24/T61 - Seleção de linhagens com melhor potencial agronomico.

\begin{tabular}{lllll}
\hline TRAT. & NOME & PE $(\mathrm{g})$ & LFM $\%$ & DEN $\left(\mathrm{g} / \mathrm{cm}^{-3}\right)$ \\
\hline 1 & JT11346 & $243 \mathrm{~b}$ & $29 \% \mathrm{a}$ & $0,381 \mathrm{Ns}$ \\
11 & JT11356 & $304 \mathrm{a}$ & $37 \% \mathrm{a}$ & $0,295 \mathrm{Ns}$ \\
35 & JT11384 & $202 \mathrm{~b}$ & $44 \% \mathrm{a}$ & $0,308 \mathrm{Ns}$ \\
P1 & J24 & $163 \mathrm{~b}$ & $43 \% \mathrm{a}$ & $0,328 \mathrm{Ns}$ \\
& & & & \\
P2 & T61 & $54 \mathrm{c}$ & $55 \% \mathrm{a}$ & $0,439 \mathrm{Ns}$ \\
\hline
\end{tabular}

TRAT $=$ Número do tratamento; $\mathrm{NOME}=$ código para nomear a linhagem gerada da população; $\mathrm{PE}=$ peso de espiga $(\mathrm{g}) ; \mathrm{DEN}=$ Densidade de colmo $\left(\mathrm{g} / \mathrm{cm}^{-3}\right)$; LFM $\%$ = Porcentagem de comprimento de lesão em colmo causada por Fusarium verticilioides; Médias seguidas pela mesma letra na mesma coluna não diferem estatisticamente pelo teste de Scott e Knott ao nível de 5\% de significância.
Tabela 6. Teste de Média - População J14/J77 - Seleção de linhagens com melhor potencial agronomico.

\begin{tabular}{lllll}
\hline TRAT. & NOME & PE $(\mathrm{g})$ & LFM $\%$ & DEN $\left(\mathrm{g} / \mathrm{cm}^{-3}\right)^{*}$ \\
2 & JJ11658 & $220 \mathrm{a}$ & $35 \% \mathrm{a}$ & $0,284 \mathrm{~b}$ \\
14 & $\mathrm{JJ} 11670$ & $237 \mathrm{a}$ & $39 \% \mathrm{a}$ & $0,320 \mathrm{ab}$ \\
39 & $\mathrm{JJ} 11695$ & $254 \mathrm{a}$ & $38 \% \mathrm{a}$ & $0,292 \mathrm{ab}$ \\
61 & $\mathrm{JJ} 11717$ & $234 \mathrm{a}$ & $49 \% \mathrm{~b}$ & $0,320 \mathrm{ab}$ \\
& & & & \\
P1 & $\mathrm{J} 77$ & $163 \mathrm{a}$ & $35 \% \mathrm{a}$ & $0,267 \mathrm{~b}$ \\
P2 & $\mathrm{J} 14$ & $57 \mathrm{c}$ & $68 \% \mathrm{c}$ & $0,327 \mathrm{ab}$ \\
\hline
\end{tabular}

TRAT $=$ Número do tratamento; NOME $=$ código para nomear a linhagem gerada da população; $\mathrm{PE}=$ peso de espiga $(\mathrm{g})$; $\mathrm{DEN}=$ Densidade de colmo $\left(\mathrm{g} / \mathrm{cm}^{-3}\right) ; \mathrm{LFM} \%=$ Porcentagem de comprimento de lesão em colmo causada por Fusarium verticilioides; Médias seguidas pela mesma letra na mesma coluna não diferem estatisticamente pelo teste de Scott e Knott ao nível de 5\% de significância. * Médias seguidas pela mesma letra na mesma coluna não diferem estatisticamente pelo teste de Tuckey ao nível de 5\% de significância

Tabela 7. Teste de Média - População G23/M20 - Seleção de linhagens com melhor potencial agronomico.

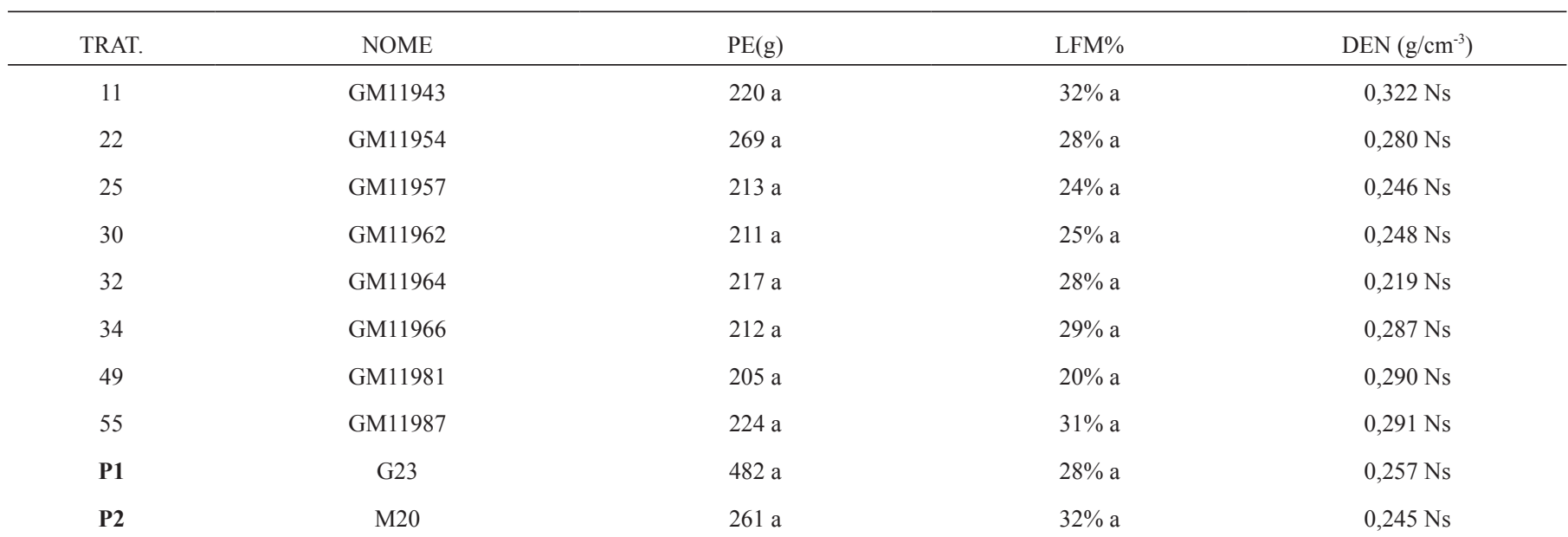

TRAT = Número do tratamento; NOME = código para nomear a linhagem gerada da população; $\mathrm{PE}=$ peso de espiga $(\mathrm{g}) ; \mathrm{DEN}=\mathrm{Densidade}$ de colmo $\left(\mathrm{g} / \mathrm{cm}^{-3}\right)$; LFM $\%$ = Porcentagem de comprimento de lesão em colmo causada por Fusarium verticilioides; Médias seguidas pela mesma letra na mesma coluna não diferem estatisticamente pelo teste de Scott e Knott ao nível de 5\% de significância. 
As linhagens oriundas da população G23/M20 não apresentaram segregação transgressiva significativa para as características avaliadas. Mas, seguindo o mesmo raciocínio do grupo anterior, a linhagem que mais se destacou foi a do tratamento 22 (GM11954) com a terceira produtividade de espigas e a nona posição no ranking não diferindo significativamente do parental mais resistente. Outro grupo de linhagens com alto potencial como fonte de resistência e produtividade foi o constutuído pelas linhagens dos tratamentos número 11(GM11943), 25 (GM11957), 30 (GM11962), 32 (GM11964), 34 (GM11966), 49 (GM11981) e 55 (GM11987).

No grupo de linhagens originárias da população J67/T66, observou-se segregação transgressiva significativa para o peso médio de espiga, sendo que o mesmo não foi observado para a densidade de colmo e a porcentagem de lesão. Assim, as linhagens dos tratamentos 2 (JT12139), 4 (JT12142), 9 (JT12147) e 10 (JT12149) apresentaram ranqueamento satisfatório sendo que possuem potencial para serem utilizadas para geração de novos híbridos e populações mais produtivas e mais resistentes.

\section{Estimativa dos componentes de variância}

Das quatro populações avaliadas, apenas a população J77/ J14 e J67/T66 apresentaram dados com distribuição normal após transformação para arc seno raiz da $\% 10^{-1}$. Assim, somente foram estimados os componentes de variância destes dois cruzamentos, sendo que os dados foram tomados por planta e não mais por parcela.

Na Tabela 9 estão as médias dos Pais 1, Pais 2, F1 e suas linhas derivadas. No cruzamento J67/T66 a média da F1 (47\%), apesar de graficamente ficar mais próxima do parental suscetível (57\%), não diferiu significativamente do parental resistente, sendo que a maior frequência foi de indivíduos resistentes. Já no cruzamento J77/ $\mathrm{J} 14$, a média da $\mathrm{F} 1$ se apresenta bem próxima à média do parental resistente, sendo de $39 \%$ e $35 \%$, respectivamente. A maior frequência de indivíduos foi suscetível, sendo resultado do background genético dos cruzamentos avaliados, que no caso do cruzamento J67/T66 foi uma mistura de dois grupos heteróticos contrastantes e o cruzamento J14/J77 envolveu linhagens do mesmo grupo heterótico.

$\mathrm{Na}$ Tabela 10, dos comparando-se as variâncias fenotípicas dos dois cruzamentos, houve maior variância fenotípica dentro do que entre no cruzamento J14/J77. Já no J67/T66 elas possuem a mesma magnitude, sendo que a variância fenotípica total foi maior no cruzamento J67/T66. Apesar de ser menor no cruzamento J14/ J77 a variância dentro correspondeu a $63 \%$ da variância fenotípica total. Este comportamento foi o inverso quando estimado a variância ambiental. No caso do cruzamento J67/T66 a variância dentro foi $74 \%$ da total, sendo que no J14/J77 elas quase se equipararam.

No caso da variância genotípica, o cruzamento J67/T66 possui uma variância genotípica entre bem maior que a dentro, o que seria de se esperar de linhagens originadas de duplo-haploidia, onde a uniformidade é bastante alta com apenas três gerações. Entretanto, no caso do cruzamento $\mathrm{J} 77 / \mathrm{J} 14$, a variância dentro foi responsável por $68 \%$ da variância total.

As linhagens oriundas desta tecnologia apesar de apresentaram grande uniformidade fenotípica, constatou-se uma grande variação dentro, ou seja, houve diferença entre plantas, que teoricamente, seriam homozigotas para todos os locus para reação da podridão de colmo. Assim, estas linhagens, apesar de apresentarem plantas uniformes, para reação a podridão de colmo constatou-se uma variação de origem genética, o que não era de se esperar, pois teoricamente todas as plantas da linhagem deveriam ser idênticas.

Esta maior estimativa entre plantas influenciou assim, a herdabilidade no sentido amplo, pois houve maior magnitude dentro da linha do que entre linhagens. Na literatura alguns autores como LI et al., (12) relatam que apesar desta técnica gerar linhagens altamente uniformes, pode haver contribuição do genótipo do indutor na produção da linhagem.

Com relação a herdabilidade restrita, que é aquela que importa ao melhorista, para ambos os cruzamentos seus valores foram de mesma magnitude, entretanto, uma delas sendo negativa, $(-0,0086)$.

Tabela 8. Teste de Média - População J67/T66- Seleção de linhagens com melhor potencial agronomico.

\begin{tabular}{lllll}
\hline TRAT. & NOME & PE $(\mathrm{g})$ & LFM $\%$ & DEN $\left(\mathrm{g} / \mathrm{cm}^{-3}\right)$ \\
\hline 2 & JT12139 & $103 \mathrm{c}$ & $30 \% \mathrm{a}$ & $0,469 \mathrm{a}$ \\
4 & JT12142 & $129 \mathrm{~b}$ & $31 \% \mathrm{a}$ & $0,288 \mathrm{~b}$ \\
9 & JT12147 & $210 \mathrm{~b}$ & $44 \% \mathrm{a}$ & $0,358 \mathrm{a}$ \\
10 & JT12149 & $194 \mathrm{~b}$ & $31 \% \mathrm{a}$ & $0,291 \mathrm{~b}$ \\
P1 & J67 & $93 \mathrm{c}$ & $27 \% \mathrm{a}$ & $0,340 \mathrm{a}$ \\
P2 & T66 & $96 \mathrm{c}$ & $57 \% \mathrm{~b}$ & $0,357 \mathrm{a}$
\end{tabular}

TRAT $=$ Número do tratamento; NOME = código para nomear a linhagem gerada da população; PE = peso de espiga $(\mathrm{g}) ; \mathrm{DEN}=\mathrm{Densidade}$ de colmo $\left(\mathrm{g} / \mathrm{cm}^{-3}\right) ; \mathrm{LFM} \%$ = Porcentagem de comprimento de lesão em colmo causada por Fusarium verticilioides; Médias seguidas pela mesma letra na mesma coluna não diferem estatisticamente pelo teste de Scott Knott ao nível de 5\% de significância.

Tabela 9. Médias do Pai 1, Pai 2, F1 e suas linhas derivadas para \% de lesão no colmo causada po Fusarium verticilioides.

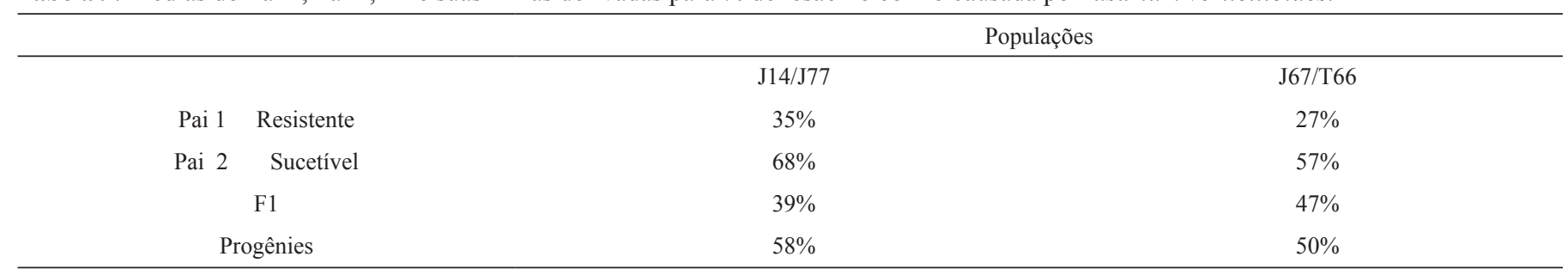


Tabela 10. Estimativa dos componentes de variância de duas populações estudadas.

\begin{tabular}{lcc}
\hline & \multicolumn{2}{c}{ Populações } \\
\hline Variância Fenotípica & $\mathrm{J} 67 / \mathrm{T} 66$ & $\mathrm{~J} 14 / \mathrm{J} 77$ \\
\hline Entre & 0,0560 & 0,0291 \\
Dentro & 0,0531 & 0,0506 \\
Total & 0,1091 & 0,0798 \\
\hline Variância Ambiental & & \\
\hline Entre & 0,0141 & 0,0137 \\
Dentro & 0,0404 & 0,0179 \\
Total & 0,0412 & 0,0237 \\
\hline Variância Genotípica & & \\
\hline Entre & 0,0419 & 0,0154 \\
Dentro & 0,0127 & 0,0327 \\
Total & 0,0547 & 0,0481 \\
\hline Variância Aditiva & 0,0152 & $-0,0086$ \\
\hline Variância de Dominância & 0,6207 & 1,6435 \\
\hline Herdabilidade Ampla & & 0,5286 \\
\hline Entre & 0,75 & 0,6458 \\
Dentro & 0,23 & $-0,2129$ \\
\hline Restrita Total & 0,28 & \\
\hline & & \\
\hline
\end{tabular}

Tabela 11. Estimativa do ganho de seleção da população J67/T66.

\begin{tabular}{lccc}
\hline & $\begin{array}{c}\text { Seleção entre } \\
\text { famílias }\end{array}$ & $\begin{array}{c}\text { Seleção dentro } \\
\text { da família }\end{array}$ & $\begin{array}{c}\text { Seleção } \\
\text { Massal }\end{array}$ \\
$\mathrm{N}^{\circ}$ de Selecionados & 3 & $9^{*}$ & 9 \\
Média Selecionadas & 0,7240 & 0,8299 & 0,5102 \\
Diferencial de Seleção & $-0,33$ & $-0,2242$ & $-0,5439$ \\
Herdabilidade Restrita & 0,5312 & 0,0057 & 0,2755 \\
Ganho de Seleção & $-0,1753$ & $-0,0013$ & $-0,1499$ \\
Ganho de Seleção (\%) & $-16,70$ & $-0,1217$ & $-14,22$ \\
\hline
\end{tabular}

* Seleção de três plantas dentro de três famílias.
Segundo Barbin (1), citando Searle (14), quando deparamos com estimativa de componente de variância negativa uma das opções a ser utilizada seria considerá-la como zero, ou seja, nula. Como a estimativa da variância aditiva foi negativa esta influenciou a herdabilidade restrita, pois também sua estimativa foi negativa.

Em ambos os cruzamentos a magnitude das estimativas da variância de dominância foi bem maior que a aditiva. Este mesmo comportamento foi observado por Kim \& Brewbaker (10), Carson \& Hooker (3) e Tesso et al (16).

Analisou-se a distribuição de frequência de indivíduos em relação à porcentagem de lesão causada por F.verticilioides das linhagens oriundas dos cruzamentos. Observou-se no cruzamento J14/J77 (Figura 1) que a média do F1 ficou entre os parentais com uma tendência de menor porcentagem de lesão, ou seja, maior resistência. Mas, em situação oposta, se encontra a distribuição de frequência das linhagens, onde há maior frequência de linhagens com maiores porcentagens de lesão, ou seja, suscetíveis à podridão de colmo.

Analisando-se a Figura 2, distribuição de frequência da população J67/T66 observou-se que a média do F1 ficou entre a média dos pais, mas não diferindo significativamente da média do parental mais resistente e que as maiores frequências foram de individuos resistentes.

Estes resultados contraditórios podem ser uma indicação de que outras formas de ação gênica, que não foram compreendidas pelo modelo, podem ter influenciado o resultado.

\section{Estimativa do ganho de seleção}

Usando os parâmetros genéticos estimados para simular a seleção de linhagens da população J67/T66 pode-se gerar uma tabela sobre o ganho de seleção da população J67/T66. Para selecionar $20 \%$ das plantas avaliadas para redução da porcentagem de lesão para um novo ciclo de recombinação usando o método de seleção massal, entre e dentro famílias tem-se os resultados da Tabela 11.

Das linhagens oriundas da população J67/T66 seriam selecionadas apenas três famílias com média de 0,72 , diferencial de seleção de-0,33, com herdabilidade no sentido restrito de 0,53 , sendo praticamente o dobro da herdabilidade na seleção massal. $\mathrm{O}$ ganho de seleção seria de $-16,70 \%$, com magnitude próxima a da seleção massal que foi de $-14,22 \%$ e bem maior que a seleção dentro que foi de $-0,12 \%$.

\section{População J14/J77}

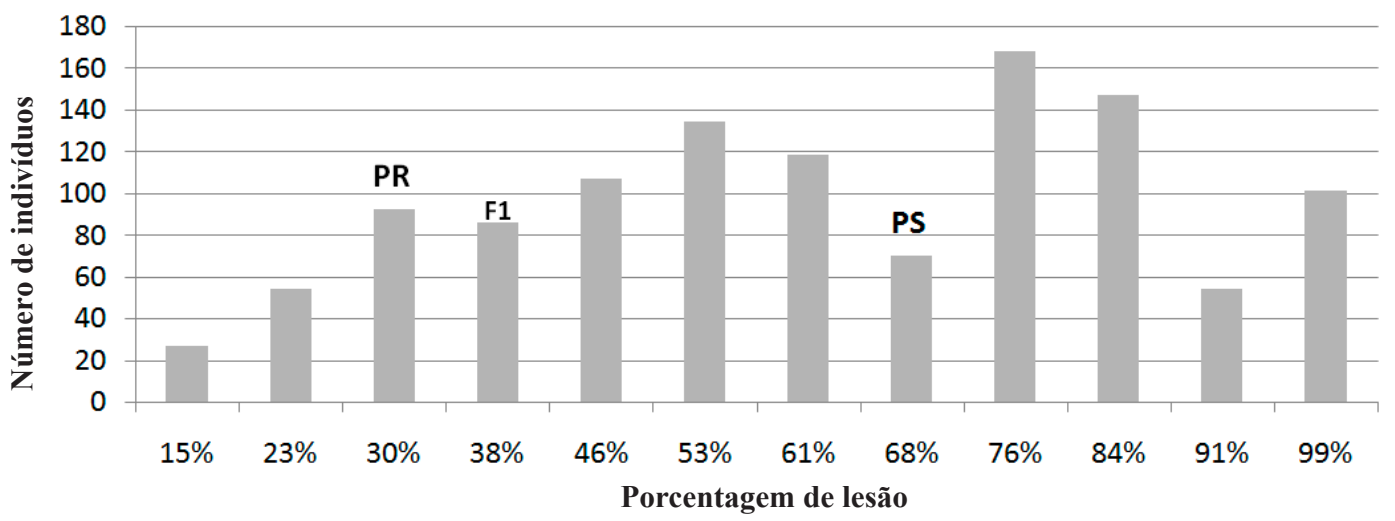

Figura 1. Distribuição de frequência de individuos em relação a porcentagem de lesão causada por Fusarium verticilioides. Onde: PR = Parental Resistente e PS = Parental Suscetível. 


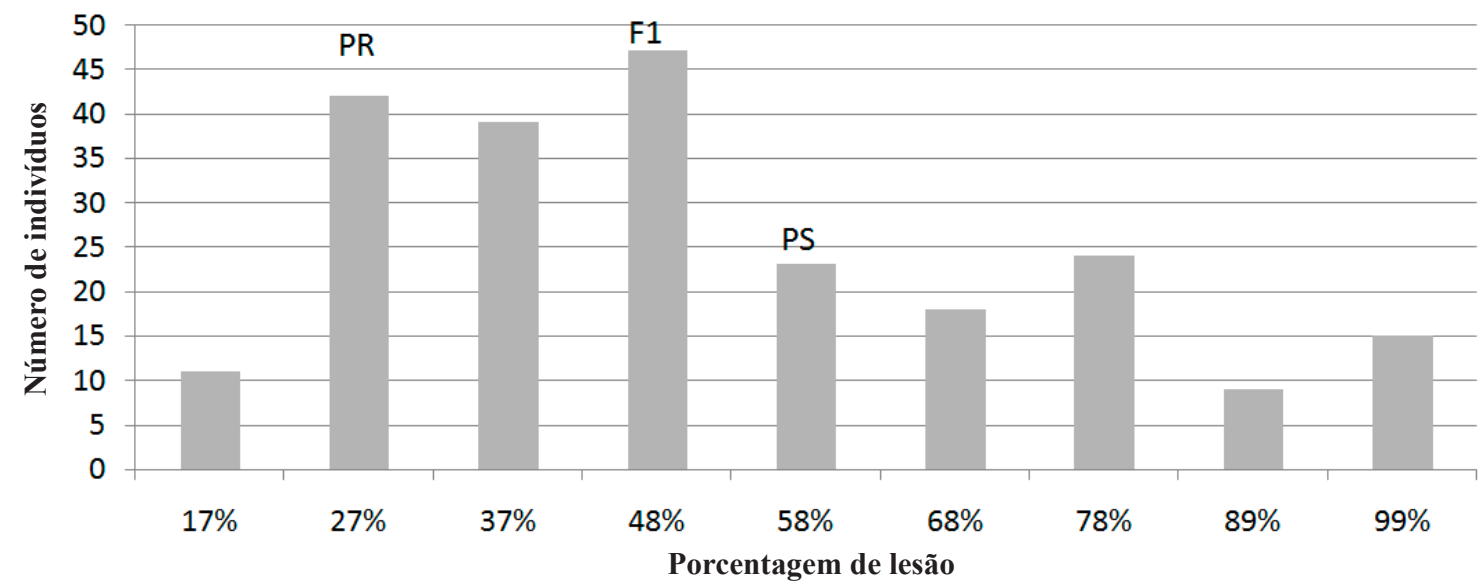

Figura 2. Distribuição de frequência de individuos em relação a porcentagem de lesão causada por Fusarium verticilioides. Onde: PR = Parental Resistente e PS = Parental Suscetível.

Observou-se variação genética entre plantas da mesma linhagem, o que não era esperado pelo uso da tecnologia duplo haploide.

A variância aditiva negativa também pode ser um indicío que o modelo utilizado não foi o ideal, sendo que para este tipo de estudo, poderia ser utilizado um modelo mais adequado a esta tecnologia de síntese de linhagens.

Os ganhos consideráveis de seleção foram alcançados com o emprego de seleção entre família e seleção massal.

A distribuição de frequência observada pode ser um indicio que os efeitos genéticos relacionados a resistência a F.verticilioides podem variar de acordo com o background genético das populações envolvidas.

\section{AGRADECIMENTOS}

Á Empresa Dow AgroSciences pela oportunidade de desenvolvimento do trabalho e também a toda a equipe da estação de pesquisa de Sorriso - MT e Jardinópolis-SP que ofereceu suporte à condução de cada etapa do trabalho e a Carol Foreman por ter dado grande suporte na literatura utilizada.

\section{REFERÊNCIAS BIBLIOGRÁFICAS}

1. Barbin, D.; Componentes de variância: teoria e aplicações. 2. Ed. rev. e amp. Piracicaba, 120p.1993.

2. Borges, Mírian F.; Resende, Mário Lúcio V.; Von Pinho, Renzo G. Inoculação artificial de colmos de milho em diferentes idades e concentrações de inóculo e sua relação com a expressão da resistência a F.verticilioides. Fitopatologia Brasileira, Brasilia, v. 26, n. 4, p. 715-720, 2001.

3. Carson M.L., Hooker, A.L. Inheritance of resistance to anthracnose stalk rot of corn caused by Colletotrichum graminicola. Phytopathology, Saint
Paul, v.71: p.1190-1196, 1981.

4. Conab. Companhia Nacional de Abastecimento.Séries Históricas de Área Plantada, Produtividade e Produção, Relativas às Safras 1976/77 a 2014/15 de Grãos, 2001 a 2014 de Café, 2005/06 a 2014/15 de Cana-de-Açúcar. Disponível em: http://www.conab.gov.br/conteudos. php? $\mathrm{a}=1252 \& \&$ Pagina_objcmsconteudos=3\#A_objcmsconteudos $>$. Acesso em: 22 de mar. 2015.

5. Cruz, C.D. Programa Genes: Biometria. Viçosa (MG). Editora UFV. 382p. 2006

6. Da Costa, RV.; DA UFLA, Fitopatologia. Podridões fúngicas de colmo na cultura do milho. Embrapa Milho e Sorgo. Circular técnica, 2008.

7. Deimling, S.; Rober, F.;Geiger, H. H. Methodik und genetic der in-vivo haploideninduktion bei mais. Vortr Pflanzenzuchtung, Berlin, v. 38, p. 203-204, 1997.

8. Fancelli, A. L.; Dourado Neto, D. Produção de milho. $2^{\text {a }}$ ed., Piracicaba, ed. Guaiba, 360p. 2004.

9. Fantin, G. M.; Duarte, A. P. Manejo de doenças na cultura do milho safrinha. Campinas: Instituto Agronômico, 99p., 2009.

10. Kim, S.K.; Brewbaker, J.; Inheritance of general resistance in maize to Puccinia sorghi Schw. Crop Science, Madison , v. 7 p.456-461, 1977.

11. Kimat, H.; Amorim,L.; Bergamin Filho, A.; Camargo,L.E.A.; Rezende, J.A.M. Manual de fitopatologia: Doenças das Plantas Cultivadas. São Paulo: Ceres, 2005.

12. LI, L.; Xiaowei, X.; Jin W.; Morphological and molecular evidences for DNA introgression in haploid induction via a high oil inducer CAUHOI in maize. Planta, Beijing, v.230, n.2, May., p.367-376, 2009.

13. Paterniani, E.; Campos, M. S. Melhoramento do milho. In: BORÉM, A. (Ed.). Melhoramento de espécies cultivadas. Viçosa, MG: UFV, 1999. p. 429-486.

14. Searle, S.R.; Fawcett, R.F.; Expected mean squares in components models having finite populations. Biometrics, Arlington, 26: 243-254, 1970.

15. Silva, O.C. da; Schipanski, C.A. Manual de identificação e manejo das doenças do milho. Castro: Fundação ABC, 2006.

16. Tesso, T.; Claflin, L.E.; Tuinstra, M.R.; Estimation of Combining ability for resistance to fusarium stalk rot in grain sorghum. Crop Science. Madison v.44 p.1195-1199, 2004. 